\title{
Optimal fiscal policy with Epstein-Zin preferences and utility-enhancing government services: lessons from Bulgaria (1999-2016)
}

\author{
Aleksandar Vasilev*
}

January 30, 2019

\begin{abstract}
This paper compares and contrasts exogenous (observed) and optimal fiscal policy in an economy with Epstein-Zin $(1989,1991)$ preferences, with consumption tax, and a common income tax, using a dynamic general-equilibrium model, calibrated to Bulgarian data (1999-2016). The focus is on the relative importance of consumption vs. income taxation, as well as on the provision of utility-enhancing public services. The main findings are: (i) The optimal steady-state income tax rate is zero; (ii) The benevolent Ramsey planner sets optimally the utility-enhancing public services, which are now $25 \%$ higher; (iii) The optimal steady-state consumption tax is approximately fifty percent higher.
\end{abstract}

Keywords: Epstein-Zin preferences, consumption tax, income tax, general equilibrium, optimal (Ramsey) fiscal policy, Bulgaria

JEL Classification Codes: D58, E26, H26

${ }^{*}$ Lecturer, Lincoln International Business School, UK. E-mail for correspondence: AVasilev@lincoln.ac.uk. 


\section{Introduction and Motivation}

Since the early 1990s, many macroeconomic studies have focused on the effects of observed fiscal policy in general equilibrium setups, and in particular comparing and contrasting it to a benchmark, or "optimal fiscal policy" regime. ${ }^{1}$ The exercise was used to inform policymakers about the taxation and spending mix in public finances, and how it needs to be adjusted to improve efficiency in the economy. The main focus of those studies, however, has been predominantly how to raise an exogenously-set level of government purchases (consumption) via distortionary capital and labor taxes. The literature overemphasized the distinction between capital and labor income taxation, and abstracted away from consumption, or value-added, taxation (VAT). ${ }^{2}$ Furthermore, in Eastern Europe, there was also a move toward a common income tax rate, and reliance on indirect (consumption/VAT and excise) taxation. ${ }^{3}$

Bulgaria, a small Eastern European economy, and a EU member-state as of 2007, adopted a public finance model that emphasized consumption-based taxation. As seen from Figure 1 on the next page, VAT revenue is the major source of tax revenue in Bulgaria ${ }^{4}$, responsible for almost half of the total tax revenue raised. ${ }^{5}$ In addition, as of 2008 both capital and labor income, as well as corporate profits are taxed at the common rate of $10 \%$. Therefore, in addition to deciding on the optimal level of public spending, a fiscal authority in the Bulgarian (and also EU) context is choosing a different set of tax rates - a common income tax rate, and a tax rate on consumption. This public finance problem is thus different from the one described in Chari, Christiano and Kehoe $(1994,1999) .{ }^{6}$

\footnotetext{
${ }^{1}$ For, example, Chari, Christiano and Kehoe (1994, 1999), and many others

${ }^{2}$ A non-exhaustive list includes Jones et al. (1997), Coleman (2000), Correia (2010), Turnovsky (2000), Laczo and Rossi (2015), Schmitt-Grohe and Uribe (2006), and Schmitt-Grohe and Uribe (2007).

${ }^{3}$ The common tax rate on income was introduced in order to discourage individuals from moving income between labor and capital to the category that is taxed at a lower rate.

${ }^{4}$ The situation is very similar for other Central and Eastern European economies as well.

${ }^{5}$ The other major source of revenue, making around a third of total tax revenues, are social contributions made by both employers and employees. Compared to consumption-based taxation, which is a tax on demand, income taxation in Bulgaria is of much smaller importance for the budget: for example, over the period 2007-2014, taxation of both individuals and corporations constitutes around $10 \%$ of overall tax revenue each

${ }^{6}$ This distinguishes our study from other papers in the literature, e.g., Coleman (2000), Turnovsky (2000), and Correia (2010), among many others. In addition, the focus of the analysis is on the steady-state
} 
Figure 1: Fiscal importance of VAT revenue in Bulgaria (1997-2012)

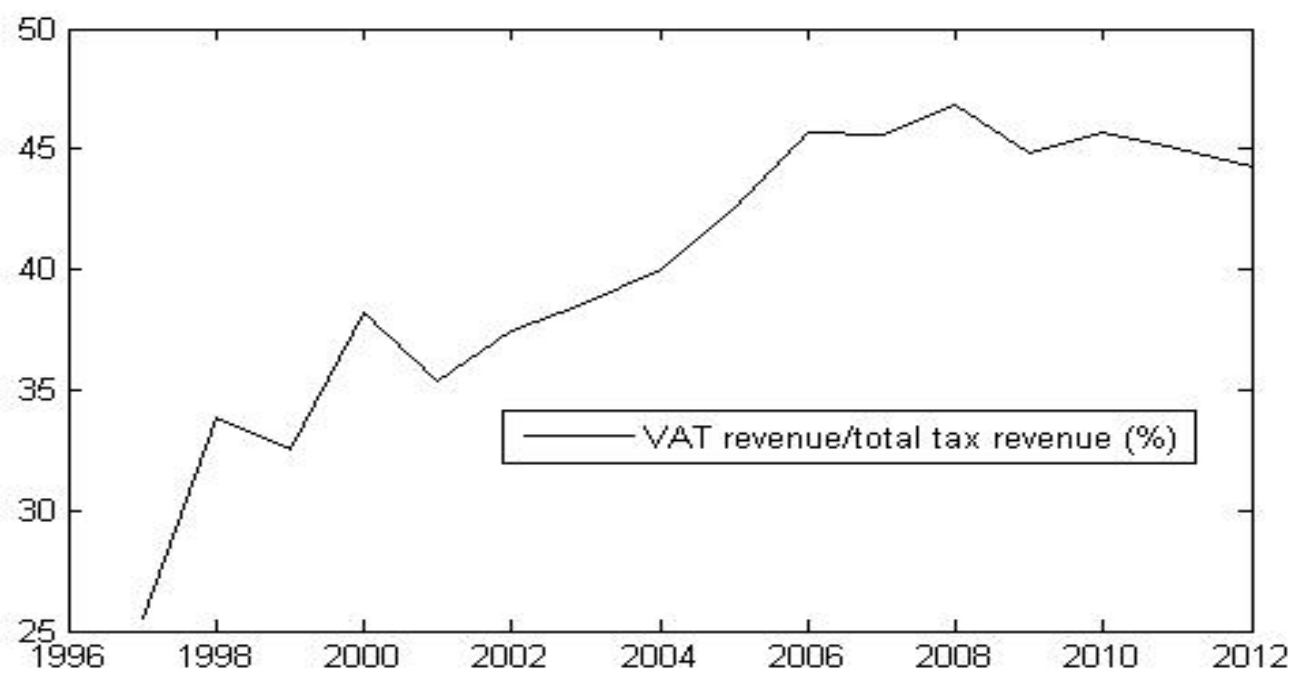

Source: WDI (2015)

This paper also extends earlier research by introducing Epstein-Zin $(1989,1991)$ recursive preference and the motive for so-called "early resolution of uncertainty" in the economy, which could produce interesting and novel results. ${ }^{7}$ The particular advantage of those preferences is that they feature constant (but unrelated) coefficients of risk aversion and elasticity of intertemporal substitution. ${ }^{8}$ After all, the two parameters are distinct features of household's preferences, and should be parameterized separately from each other. Consumer preferences play a crucial role in any economic model; after all, we derive consumers' optimal decision rules from those, in order to evaluate the quantitative effects of different fiscal allocations, in contrast to Correia (2010), who focuses on optimized impulse responses, and Schmidt-Grohe and Uribe $(2006,2007)$ who also study the adjustment of fiscal policy instruments along the transition path; instead, here we are more interested in the average rates of income and consumption taxes, given that consumption taxation is responsible for almost a half of total government revenue.

${ }^{7}$ We differ from Karantounias (2018) in important way, as in this paper we also allow for optimally-chosen government consumption. In addition, Karantounias (2018) does not consider consumption taxation.

${ }^{8}$ In the usual formulation with time-separable preferences, one is reciprocal of the other. This is a problem as in data both a low elasticity of inter-temporal substitution, and low risk aversion have been measured. As pointed in Weil (1990), researchers in macroeconomics should distinguish between risk aversion and the willingness to substitute consumption over time in their models. 
policies.

The paper then proceeds to characterize optimal (Ramsey) fiscal policy in the context of the problem described above and then to evaluate it relative to the exogenous (observed) fiscal policy regime. Similar to earlier literature, e.g. Judd (1985), Chamley (1986), and Zhu (1992), allowing distortionary taxation in a dynamic general-equilibrium framework creates interesting trade-offs: On the one hand, valuable government services directly increase household's utility. On the other, the proportional income taxes will negatively affect the incentives to supply labor and to accumulate physical capital. In turn, higher taxes reduce not only income, but also consumption, which is actually hit twice due to a second round of taxation, this time at the point of consumption. Both types of taxes lower welfare, both directly, and indirectly, by generating less tax revenue which could be spent on valuable public services. The optimal fiscal policy problem discussed in this paper is to choose consumption and a common income tax rate to finance both utility-enhancing and redistributive government expenditure, while at the same time minimizing both the allocative distortions created in the economy, as a result of the presence of proportional taxation. The main findings from the computational experiments performed are: (i) The optimal steady-state income tax rate is zero; (ii) The benevolent Ramsey planner provides the optimal amount of the utility-enhancing public services, which are now 25\% higher; (iii) The optimal steady-state consumption tax needed to finance the optimal level of government spending is fifty percent, as compared to the exogenous policy case.

The rest of the paper is organized as follows: Section 2 describes the model framework and describes the decentralized equilibrium system, Section 4 discusses the calibration procedure, and Section 4 presents the steady-state model solution. Sections 5 proceeds with the optimal taxation (Ramsey) policy problem and evaluates the long-run effects on the economy. Section 6 concludes the paper. 


\section{Model Description}

The model closely follows Vasilev (2018a). There is a representative households which derives utility out of consumption, leisure, and government services. The time available to households can be spent in productive use or as leisure. The government taxes consumption spending and levies a common tax on all income, in order to finance purchases of government consumption goods, and government transfers. On the production side, there is a representative firm, which hires labor and capital to produce a homogenous final good, which could be used for consumption, investment, or government purchases.

\subsection{Household}

There is a representative household, which maximizes a utility function, which features recursive preferences as in Epsten and Zin (1989, 1991) and Weil (1990):

$$
V_{t}=\left[(1-\beta)\left[c_{t}^{\nu_{1}}\left(1-h_{t}\right)^{\nu_{2}}\left(g_{t}^{c}\right)^{1-\nu_{1}-\nu_{2}}\right]^{\frac{1-\gamma}{\theta}}+\beta\left[E_{t} V_{t+1}^{1-\gamma}\right]^{\frac{1}{\theta}}\right]^{\frac{\theta}{1-\gamma}}
$$

where

$$
\theta=\frac{1-\gamma}{1-\frac{1}{\psi}}
$$

and $V_{t}$ is the value function as of period $t, 0<\nu_{1}, \nu_{2}, 1-\nu_{1}-\nu_{2}<1$ are the utility weights attached to consumption, leisure, and government services, respectively; $\left[E_{t} V_{t+1}^{1-\gamma}\right]^{\frac{1}{\theta}}$ is the risk-adjusted expectation operator at of period $t, c_{t}$ denotes household's private consumption in period $t, h_{t}$ are hours worked in period $t, 0<\beta<1$ is the discount factor. ${ }^{9}$

With Epstein-Zin preferences, the elasticity of intertemporal substitution (EIS), and the coefficient of relative risk aversion (CRRA) are separated. More specifically, $\gamma \geq 0$ is the parameter that controls risk aversion, while $\psi \geq 0$ is the IES. ${ }^{10}$ Note that for values of $\gamma>1$, and $\psi>1$, the agent has a preference for "an early resolution of uncertainty" (Kreps and

\footnotetext{
${ }^{9}$ Importantly, these preferences are stationary in the sense of Koopmans (1960).

${ }^{10}$ Therefore, this class of preferences responds to Hall's (1988) critique. In contrast, with other functional forms the elasticity of substitution and the coefficient of relative risk aversion are reciprocals of one another.
} 
Porteus 1978, Weil 1990). ${ }^{11}$ In other words, the household is averse to volatility in future utility, and more specifically, the recursive utility formulation adds curvature with respect to future risks. ${ }^{12}$

The household starts with an initial stock of physical capital $k_{0}>0$, and has to decide how much to add to it in the form of new investment. The law of motion for physical capital is

$$
k_{t+1}=i_{t}+(1-\delta) k_{t}
$$

and $0<\delta<1$ is the depreciation rate. Next, the real interest rate is $r_{t}$, hence the before-tax capital income of the household in period $t$ equals $r_{t} k_{t}$. In addition to capital income, the household can generate labor income. Hours supplied to the representative firm are rewarded at the hourly wage rate of $w_{t}$, so pre-tax labor income equals $w_{t} h_{t}$. Lastly, the household owns the firm in the economy and has a legal claim on all the firm's profit, $\pi_{t}$.

Next, the household's problem can be now simplified to

$$
\max _{\left\{c_{t}, h_{t}, k_{t+1}\right\}_{t=0}^{\infty}} V_{t}=\left[(1-\beta)\left[c_{t}^{\nu_{1}}\left(1-h_{t}\right)^{\nu_{2}}\left(g_{t}^{c}\right)^{1-\nu_{1}-\nu_{2}}\right]^{\frac{1-\gamma}{\theta}}+\beta\left[E_{t} V_{t+1}^{1-\gamma}\right]^{\frac{1}{\theta}}\right]^{\frac{\theta}{1-\gamma}}
$$

s.t.

$$
\left(1+\tau_{t}^{c}\right) c_{t}+k_{t+1}-(1-\delta) k_{t}=\left(1-\tau_{t}^{y}\right)\left[w_{t} h_{t}+r_{t} k_{t}\right]+g_{t}^{t}+\pi_{t}
$$

where $\tau_{t}^{c}$ is the (potentially time-varying) tax on consumption, $\tau^{y}$ is the proportional income tax rate $\left(0<\tau^{c}, \tau^{y}<1\right)$, levied on both labor and capital income (also potentially

${ }^{11}$ Note that, as in Epstein and Zin (1991), early resolution of uncertainty requires

$$
1-\gamma<1-\frac{1}{\psi} \quad \text { or } \quad \frac{1}{\psi}<\gamma
$$

For $\psi, \gamma>1$ the condition above is satisfied.

${ }^{12}$ As pointed out in Kaltenbrunner and Lochstoer (2010), investors with Epstein-Zin preferences also demand a premium for holding asserts, which are correlated with shocks to expected consumption growth. When households have preferences for early resolution of uncertainty, these shocks carry a positive price of "long-run risk" (Bansal and Yaron 2004). In applied work, this risk can be potentially defined using shocks to the continuation value, normalized by consumption, via shocks to the wealth-to-consumption ratio, or shocks to the expected future consumption growth. 
time-varying), and $g_{t}^{t}$ denotes government transfers. The household takes the two tax rates $\left\{\tau^{c}, \tau^{y}\right\}$, government spending categories, $\left\{g_{t}^{c}, g_{t}^{t}\right\}_{t=0}^{\infty}$, profit $\left\{\pi_{t}\right\}_{t=0}^{\infty}$, the realized technology process $\left\{A_{t}\right\}_{t=0}^{\infty}$, prices $\left\{w_{t}, r_{t}\right\}_{t=0}^{\infty}$, and chooses $\left\{c_{t}, h_{t}, k_{t+1}\right\}_{t=0}^{\infty}$ to maximize its utility subject to the budget constraint. ${ }^{13}$ The constraint optimization problem generates the following optimality conditions:

$$
\begin{aligned}
V_{t}: V_{t}-\left[(1-\beta)\left[c_{t}^{\nu_{1}}\left(1-h_{t}\right)^{\nu_{2}}\left(g_{t}^{c}\right)^{1-\nu_{1}-\nu_{2}}\right]^{\frac{1-\gamma}{\theta}}+\beta\left[E_{t} V_{t+1}^{1-\gamma}\right]^{\frac{1}{\theta}}\right]^{\frac{\theta}{1-\gamma}}=0 \\
c_{t}: \quad \nu\left[(1-\beta)\left[c_{t}^{\nu_{1}}\left(1-h_{t}\right)^{\nu_{2}}\left(g_{t}^{c}\right)^{1-\nu_{1}-\nu_{2}}\right]^{\frac{1-\gamma}{\theta}}+\beta\left[E_{t} V_{t+1}^{1-\gamma}\right]^{\frac{1}{\theta}}\right]^{\frac{\theta}{1-\gamma}-1} \times \\
(1-\beta) c_{t}^{\frac{\nu_{1}(1-\gamma)}{\theta}-1}\left(1-h_{t}\right)^{\frac{\nu_{2}(1-\gamma)}{\theta}}\left(g_{t}^{c}\right)^{\frac{\left(1-\nu_{1}-\nu_{2}\right)(1-\gamma)}{\theta}}=\lambda_{t}\left(1+\tau_{t}^{c}\right) \\
h_{t}: \quad(1-\nu)\left[(1-\beta)\left[c_{t}^{\nu_{1}}\left(1-h_{t}\right)^{\nu_{2}}\left(g_{t}^{c}\right)^{1-\nu_{1}-\nu_{2}}\right]^{\frac{1-\gamma}{\theta}}+\beta\left[E_{t} V_{t+1}^{1-\gamma}\right]^{\frac{1}{\theta}}\right]^{\frac{\theta}{1-\gamma}-1} \times \\
k_{t+1: \quad} \quad \lambda_{t}=\beta E_{t} \lambda_{t+1}\left[1+\left(1-\tau_{t+1}^{y}\right) r_{t+1}-\delta\right] \\
T V C: c_{t \rightarrow \infty}^{\frac{\nu(1-\gamma)}{\theta}}\left(1-h_{t}\right)^{\frac{(1-\nu)(1-\gamma)}{\theta}}-1\left(g_{t}^{c} k_{t+1}^{\frac{\left(1-\nu_{1}-\nu_{2}\right)(1-\gamma)}{\theta}}=0\right.
\end{aligned}
$$

where $\lambda_{t}$ is the Lagrangean multiplier attached to household's budget constraint in period $t$. The interpretation of the first-order conditions above is as follows: the first one states that for each household, besides caring for the short-run (period $t$ vs. period $t+1$ utility), the household cares also for the "long run", in the sense that the entire sequence of future consumption and leisure - captured by continuation values - directly affects the state of the economy in $t+1$. The second equation states that when choosing labor supply optimally, at the margin, each hour spent by the household working for the firm should balance the benefit from doing so in terms of additional income generates, and the cost measured in terms of lower utility of leisure. The third equation is the so-called "Euler condition," which describes how the household chooses to allocate physical capital over time. The last condition is called the "transversality condition" (TVC): it states that at the end of the horizon, the value of physical capital should be zero.

\footnotetext{
${ }^{13}$ Note that by choosing $k_{t+1}$ the household is implicitly setting investment $i_{t}$ optimally.
} 


\subsection{Firm problem}

There is a representative firm in the economy, which produces a homogeneous product. The price of output is normalized to unity. The production technology is Cobb-Douglas and uses both physical capital, $k_{t}$, and labor hours, $h_{t}$, to maximize static profit

$$
\Pi_{t}=A_{t} k_{t}^{\alpha} h_{t}^{1-\alpha}-r_{t} k_{t}-w_{t} h_{t}
$$

where $A_{t}$ denotes the level of technology in period $t$. Since the firm rents the capital from households, the problem of the firm is a sequence of static profit maximizing problems. In equilibrium, there are no profits, and each input is priced according to its marginal product, i.e.:

$$
\begin{array}{ll}
k_{t}: & \alpha \frac{y_{t}}{k_{t}}=r_{t}, \\
h_{t}: & (1-\alpha) \frac{y_{t}}{h_{t}}=w_{t} .
\end{array}
$$

In equilibrium, given that the inputs of production are paid their marginal products, $\pi_{t}=0$, $\forall t$.

\subsection{Government}

In the model setup, the government is levying taxes on labor and capital income, as well as consumption, in order to finance spending on wasteful government purchases, and government transfers. The government budget constraint is as follows:

$$
g_{t}^{c}+g_{t}^{t}=\tau_{t}^{c} c_{t}+\tau_{t}^{y}\left[w_{t} h_{t}+r_{t} k_{t}\right]
$$

Tax rates and government consumption-to-output ratio would be chosen to match the average share in data, and government transfers would be determined residually in each period so that the government budget is always balanced.

\subsection{Dynamic Competitive Equilibrium (DCE)}

For a given process followed by technology $\left\{A_{t}\right\}_{t=0}^{\infty}$ average tax rates $\left\{\tau^{c}, \tau^{y}\right\}$, initial capital stock $\left\{k_{0}\right\}$, the decentralized dynamic competitive equilibrium is a list of sequences $\left\{c_{t}, i_{t}, k_{t}, h_{t}, V_{t}\right\}_{t=0}^{\infty}$ for the household, a sequence of government purchases and transfers 
$\left\{g_{t}^{c}, g_{t}^{t}\right\}_{t=0}^{\infty}$, and input prices $\left\{w_{t}, r_{t}\right\}_{t=0}^{\infty}$ such that (i) the household maximizes its utility function subject to its budget constraint; (ii) the representative firm maximizes profit; (iii) government budget is balanced in each period; (iv) all markets clear.

\section{Data and Model Calibration}

To characterize the business cycle fluctuations in Bulgaria, we will focus on the period following the introduction of the currency board (1999-2016). Quarterly data on output, consumption and investment was collected from National Statistical Institute (2017), while the real interest rate is taken from Bulgarian National Bank Statistical Database (2017). The calibration strategy described in this section follows a long-established tradition in modern macroeconomics: first, as in Vasilev (2016), the discount factor, $\beta=0.982$, is set to match the steady-state capital-to-output ratio in Bulgaria, $k / y=13.964$, in the steady-state Euler equation. The labor share parameter, $1-\alpha=0.571$, is obtained as in Vasilev (2017), and equals the average value of labor income in aggregate output over the period 1999-2016. This value is slightly higher as compared to other studies on developed economies, due to the overaccumulation of physical capital, which was part of the ideology of the totalitarian regime, which was in place until 1989.

Next, the average income tax rate was set to $\tau^{y}=0.1$. This is the average effective tax rate on income between 1999-2007, when Bulgaria used progressive income taxation, and equal to the proportional income tax rate introduced as of 2008. Similarly, the tax rate on consumption is set to its value over the period, $\tau^{c}=0.2$. As in Herberger (2013), the relative risk aversion parameter and the IES are set to $\gamma=2$ and $\psi=0.043$, respectively. Next, the relative weight attached to the utility out of consumption in the household's utility function, $\nu_{1}$, is calibrated to match that in steady-state consumers would supply one-third of their time endowment to working. This is in line with the estimates for Bulgaria (Vasilev 2017a) as well over the period studied. The relative weight attached to government services was set in line with the observed shares of public and private consumption in national accounts, thus $1-\nu_{1}-\nu_{2}=0.07$. Residually, $\nu_{2}=0.62$, which means that leisure is twice more valuable than private consumption, a result which perfectly aligns with the literature. Next, 
the steady-state depreciation rate of physical capital in Bulgaria, $\delta=0.013$, was taken from Vasilev (2017b). It was estimated as the average quarterly depreciation rate over the period 1999-2014. parameters used in the paper.

Table 1: Model Parameters

\begin{tabular}{llll}
\hline \hline Parameter & Value & Description & Method \\
\hline$\beta$ & 0.982 & Discount factor & Calibrated \\
$\alpha$ & 0.429 & Capital Share & Data average \\
$1-\alpha$ & 0.571 & Labor Share & Calibrated \\
$\gamma$ & 2.000 & Relative risk aversion parameter & Set \\
$\psi$ & 0.043 & Intertemporal elasticity of substitution & Set \\
$\nu_{1}$ & 0.310 & Utility weight attached to consumption & Calibrated \\
$\nu_{2}$ & 0.620 & Utility weight attached to leisure & Calibrated \\
$1-\nu_{1}-\nu_{2}$ & 0.070 & Utility weight attached to public cons. & Calibrated \\
$\delta$ & 0.013 & Depreciation rate on physical capital & Data average \\
$\tau^{y}$ & 0.100 & Average tax rate on income & Data average \\
$\tau^{c}$ & 0.200 & VAT/consumption tax rate & Data average \\
\hline
\end{tabular}

\section{Steady-State}

Once the values of model parameters were obtained, the steady-state equilibrium system solved, the "big ratios" can be compared to their averages in Bulgarian data. The results are reported in Table 2 below. The steady-state level of output was normalized to unity (hence the level of technology $A$ differs from one, which is usually the normalization done in other studies), which greatly simplified the computations. Next, the model matches consumptionto-output and government purchases ratios by construction; The investment ratios are also closely approximated, despite the closed-economy assumption and the absence of foreign trade sector. The shares of income are also identical to those in data, which is an artifact of the assumptions imposed on functional form of the aggregate production function. The after-tax return, where $\bar{r}=\left(1-\tau^{y}\right) r-\delta$ is also relatively well-captured by the model. Lastly, given the absence of debt, and the fact that transfers were chosen residually to balance the 
government budget constraint, the result along this dimension is understandably not so close to the average ratio in data.

Table 2: Data Averages and Long-run Solution

\begin{tabular}{llll}
\hline \hline Variable & Description & Data & Model \\
\hline$y$ & Steady-state output & $\mathrm{N} / \mathrm{A}$ & 1.000 \\
$c / y$ & Consumption-to-output ratio & 0.648 & 0.674 \\
$i / y$ & Investment-to-output ratio & 0.201 & 0.175 \\
$k / y$ & Capital-to-output ratio & 13.96 & 13.96 \\
$g^{c} / y$ & Government consumption-to-output ratio & 0.151 & 0.151 \\
$w h / y$ & Labor income-to-output ratio & 0.571 & 0.571 \\
$r k / y$ & Capital income-to-output ratio & 0.429 & 0.429 \\
$h$ & Share of time spent working & 0.333 & 0.333 \\
$\bar{r}$ & After-tax net return on capital & 0.014 & 0.016 \\
\hline
\end{tabular}

\section{The Ramsey problem (Optimal fiscal policy under full commitment)}

In this section, we solve for the optimal fiscal policy scenario under full commitment. More specifically, the government will be modelled as a benevolent planner, who has the same preferences as the people in the economy, i.e., it will choose to maximize the household's utility function, while at the same time taking into account the optimality conditions by both the household and the firm, or the equations describing the DCE. ${ }^{14}$ The fiscal instruments at government's disposal are consumption and income tax rate, and the level of public consumption spending. ${ }^{15}$ In this section we allow only for distortionary, or proportional,

\footnotetext{
${ }^{14}$ Note that when the household and the firm are making optimal choices, they are taking all fiscal policy variables as given. Also note that the benevolent government treats everyone the same.

${ }^{15}$ Note that the government transfers will be held fixed at the level computed from the equilibrium under the exogenous policy case.
} 
taxes, thus the optimal allocations are only "second-best." ${ }^{16}$ In addition, it will be assumed that the government can also fully and credibly commit to the future sequence of taxes and spending until the end of the optimization period, so the policy is time-consistent. Under the Ramsey framework, the choice variables for the government are $\left\{c_{t}, h_{t}, g_{t}^{c}, k_{t+1}, w_{t}, r_{t}\right\}_{t=0}^{\infty}$ plus the two tax rates $\left\{\tau_{t}^{c}, \tau_{t}^{y}\right\}_{t=0}^{\infty}$. The initial conditions for the state variable $k_{0}$, as well as the realized sequence of government transfers $\left\{g_{t}^{t}\right\}_{t=0}^{\infty}$ and the fixed level of total factor productivity A are taken as given. The optimal policy problem is then recast as a setup where the government chooses after-tax input prices $\tilde{w}_{t}$ and $\tilde{r}_{t}$ directly, where

$$
\begin{aligned}
& \tilde{w}_{t}=\left(1-\tau_{t}^{y}\right) w_{t} \\
& \tilde{r}_{t}=\left(1-\tau_{t}^{y}\right) r_{t} .
\end{aligned}
$$

Thus, government budget constraint is now represented by

$$
\tau_{t} c_{t}+A k_{t}^{\alpha} h_{t}^{1-\alpha}-\tilde{r}_{t} k_{t}-\tilde{w}_{t} h_{t}=g_{t}^{c}+g_{t}^{t}
$$

The Ramsey problem then becomes

$$
\max _{\left\{c_{t}, h_{t}, g_{t}^{c}, k_{t+1}, \tilde{w}_{t}, \tilde{r}_{t}, \tau_{t}^{c}\right\}_{t=0}^{\infty}} V_{t}=\left[(1-\beta)\left[c_{t}^{\nu_{1}}\left(1-h_{t}\right)^{\nu_{2}}\left(g_{t}^{c}\right)^{1-\nu_{1}-\nu_{2}}\right]^{\frac{1-\gamma}{\theta}}+\beta\left[E_{t} V_{t+1}^{1-\gamma}\right]^{\frac{1}{\theta}}\right]^{\frac{\theta}{1-\gamma}}
$$

s.t.

$$
\begin{aligned}
& (1-\nu)\left(1+\tau_{t}^{c}\right) c_{t}=\nu\left(1-h_{t}\right) \tilde{w}_{t} \\
& \left(1+\tau_{t+1}^{c}\right) V_{t}^{1-\frac{1-\gamma}{\theta}} c_{t}^{\frac{\nu_{1}(1-\gamma)}{\theta}-1}\left(1-h_{t}\right)^{\frac{\nu_{2}(1-\gamma)}{\theta}}\left(g_{t}^{c}\right)^{\frac{\left(1-\nu_{1}-\nu_{2}\right)(1-\gamma)}{\theta}}= \\
& \beta\left(1+\tau_{t}^{c}\right) E_{t} V_{t+1}^{1-\frac{1-\gamma}{\theta}} c_{t+1}^{\frac{\nu_{1}(1-\gamma)}{\theta}}-1 \\
& \left(1-h_{t+1}\right)^{\frac{\nu_{2}(1-\gamma)}{\theta}}\left(g_{t+1}^{c}\right)^{\frac{\left(1-\nu_{1}-\nu_{2}\right)(1-\gamma)}{\theta}}\left[1+\tilde{r}_{t+1}-\delta\right] \\
& A k_{t}^{\alpha} h_{t}^{1-\alpha}=c_{t}+k_{t+1}-(1-\delta) k_{t}+g_{t}^{c} \\
& \tau_{t} c_{t}+A k_{t}^{\alpha} h_{t}^{1-\alpha}-\tilde{r}_{t} k_{t}-\tilde{w}_{t} h_{t}=g_{t}^{c}+g_{t}^{t}
\end{aligned}
$$

\footnotetext{
${ }^{16} \mathrm{In}$ case the government is allowed to use lump-sum taxation, it can achieve the first-best (Pareto) allocation.
} 
In order to solve the problem we set up the corresponding Lagrangean (use $\mu$-s for Lagrangean multipliers).

$$
\begin{array}{r}
\mathcal{L}=\left[(1-\beta)\left[c_{t}^{\nu_{1}}\left(1-h_{t}\right)^{\nu_{2}}\left(g_{t}^{c}\right)^{1-\nu_{1}-\nu_{2}}\right]^{\frac{1-\gamma}{\theta}}+\beta\left[E_{t} V_{t+1}^{1-\gamma}\right]^{\frac{1}{\theta}}\right]^{\frac{\theta}{1-\gamma}} \\
+\beta^{t} \mu_{t}^{1}\left[(1-\nu)\left(1+\tau_{t}^{c}\right) c_{t}-\nu\left(1-h_{t}\right) \tilde{w}_{t}\right] \\
+\beta^{t} \mu_{t}^{2}\left[\left(1+\tau_{t+1}^{c}\right) V_{t}^{1-\frac{1-\gamma}{\theta}} c_{t}^{\frac{\nu_{1}(1-\gamma)}{\theta}-1}\left(1-h_{t}\right)^{\frac{\nu_{2}(1-\gamma)}{\theta}}\left(g_{t}^{c}\right)^{\frac{\left(1-\nu_{1}-\nu_{2}\right)(1-\gamma)}{\theta}}\right. \\
\left.-\beta\left(1+\tau_{t}^{c}\right) E_{t} V_{t+1}^{1-\frac{1-\gamma}{\theta}} c_{t+1}^{\frac{\nu_{1}(1-\gamma)}{\theta}-1}\left(1-h_{t+1}\right)^{\frac{\nu_{2}(1-\gamma)}{\theta}}\left(g_{t+1}^{c}\right)^{\frac{\left(1-\nu_{1}-\nu_{2}\right)(1-\gamma)}{\theta}}\left[1+\tilde{r}_{t+1}-\delta\right]\right] \\
+\beta^{t} \mu_{t}^{3}\left[A k_{t}^{\alpha} h_{t}^{1-\alpha}-c_{t}-k_{t+1}+(1-\delta) k_{t}-g_{t}^{c}\right] \\
+\beta^{t} \mu_{t}^{4}\left[\tau_{t} c_{t}+A k_{t}^{\alpha} h_{t}^{1-\alpha}-\tilde{r}_{t} k_{t}-\tilde{w}_{t} h_{t}-g_{t}^{c}-g_{t}^{t}\right]
\end{array}
$$

As in Vasilev (2018d), we will shut down all stochasticity (uncertainty) and focus on the steady-state allocations and prices. We solve the problem numerically and report the results in Table 3 below against the values from the exogenous (observed) policy case.

Total discounted welfare is higher under the Ramsey regime: As in Lucas (1990), parameter $\xi$ is introduced to measure the welfare gain in terms of higher steady-state consumption (24\%) when the economy moves to the optimal scal policy case. Next, private consumption in the optimal policy case is higher (even though the consumption share is lower, which is since output is now much higher), while private capital- and investment shares are higher, and thus the interest rate is lower. The model generates a zero long-run income tax, which consistent with the findings in earlier studies, e.g. Judd (1985), Chamley (1986), and Zhu (1992). This leads to higher capital input and labor supplied in steady-state, which in turn translates into higher output and investment. Under Ramsey, the steady-state private consumption is lower, but public consumption overcompensates, so overall welfare increases despite the increase in hours. In other words, the government internalizes (at least partially) the externality of the utility-enhancing public services when maximizing household's overall utility. ${ }^{17}$ Finally, in order to finance the increased government consumption spending, consumption tax rate has to almost double - from $20 \%$ to $34 \%$. In contrast to the income tax, the consumption tax is less distortionary, as it is a tax on demand, rather than tax on productive inputs. Therefore,

\footnotetext{
${ }^{17}$ However, given that $1-\nu_{1}-\nu_{2}$ is significantly lower than unity, government purchases do not change much, especially as a share of output.
} 
Table 3: Data Averages and Long-run Solution

\begin{tabular}{lllll}
\hline \hline Variable & Description & Data & $\begin{array}{l}\text { Model } \\
\text { (exo policy) }\end{array}$ & $\begin{array}{l}\text { Model } \\
\text { (optimal) }\end{array}$ \\
\hline$y$ & Steady-state output & N/A & 1.000 & 1.244 \\
$c / y$ & Consumption-to-output ratio & 0.648 & 0.674 & 0.649 \\
$i / y$ & Investment-to-output ratio & 0.201 & 0.175 & 0.186 \\
$k / y$ & Capital-to-output ratio & 13.96 & 13.96 & 14.30 \\
$g^{c} / y$ & Government consumption-to-output ratio & 0.151 & 0.151 & 0.150 \\
$w h / y$ & Labor income-to-output ratio & 0.571 & 0.571 & 0.571 \\
$r k / y$ & Capital income-to-output ratio & 0.429 & 0.429 & 0.429 \\
$h$ & Share of time spent working & 0.333 & 0.333 & 0.367 \\
$\bar{w}$ & After-tax wage & - & 1.543 & 1.543 \\
$\bar{r}$ & After-tax net return on capital & 0.014 & 0.016 & 0.016 \\
$\tau^{y}$ & Income tax rate & 0.100 & 0.100 & 0.000 \\
$\tau^{c}$ & Consumption tax rate & 0.200 & 0.200 & 0.339 \\
$\xi$ & Welfare gain (\% cons.) & - & 0.000 & 24.03 \\
\hline
\end{tabular}

the optimal policy suggests abolishing all direct taxation, and adopt a public finance model that relies exclusively on indirect taxation. These results are new and could be of interest to policy makers.

\section{Conclusions}

This paper explores the effects of fiscal policy in an economy with Epstein-Zin $(1989,1991)$ preferences, with indirect (consumption) taxes, and all (labor and capital) income being taxed at the same rate. To this end, a dynamic general-equilibrium model, calibrated to Bulgarian data (1999-2016), is augmented with a government sector. Two regimes are compared and contrasted - the exogenous (observed) vs. optimal policy (Ramsey) case. The focus of the paper is on the relative importance of consumption vs. income taxation, as well as on the provision of utility-enhancing public services. Bulgarian economy was chosen as a case study due to its major dependence on consumption taxation as a source of tax revenue. 
The main findings from the computational experiments performed in the paper are: (i) The optimal steady-state income tax rate is zero; (ii) The benevolent Ramsey planner provides the optimal amount of the utility-enhancing public services, which are now $25 \%$ higher; (iii) The optimal steady-state consumption tax needed to finance the optimal level of government spending is more than fifty percent higher, as compared to the exogenous policy case.

\section{References}

Bansal, R. and A. Yaron (2004). "Risks for the Long Run: A Potential Resolution of Asset Pricing Puzzles," Journal of Finance 59: 1481-509.

Bulgarian National Bank. 2017. Bulgarian National Bank Statistics. Available on-line at www.bnb.bg. Accessed on Oct. 21, 2017.

Chamley C (1986): Optimal Taxation of Capital Income in General Equilibrium. Econometrica, 54:604-622.

Chari VV, Kehoe P (1994): Optimal Fiscal Policy in a Real Business Cycle Model. Journal of Political Economy, 102(4):617-652.

Chari VV, Kehoe P (1999): Optimal Fiscal and Monetary Policy. In: Taylor J, Woodford M (eds): Handbook of Macroeconomics, vol.1(Amsterdam: North-Holland).

Coleman, W. (2000) "Welfare and Optimum Dynamic Taxation of Consumption and Income," Journal of Public Economics 76(1), 1-39.

Correia, I. (2010) "Consumption Taxes and Redistribution," American Economic Review, $100(4), 1673-1694$.

Epstein, L. and Zin, S. (1989) "Substitution, Risk Aversion, and the Temporal Behavior of Consumption and Asset Returns: A Theoretical Framework," Econometrica 57: 937-69. 
Epstein, L. and Zin, S. (1991) "Substitution, Risk Aversion, and the Temporal Behavior of Consumption and Asset Returns: An Empirical Analysis," Journal of Political Economy 99(2): 263-286.

Hall, R. E. (1988). "Intertemporal substitution in consumption," Journal of Political Economy 96, 339-357.

Heiberger, C. (2017) "Asset Prices, Epstein Zin Utility, and Endogenous Economic Disasters," Unpublished Dissertation, University of Augsburg, Germany.

Jones, L., R.E. Manuelli and P. Rossi (1997) "On the Optimal Taxation of Capital Income," Journal of Economic Theory 73, 93-117.

Judd, K. (1985) "Redistributive Taxation in a Simple Perfect Foresight Model." Journal of Public Economics, 28:59-83.

Kaltenbrunner, G. and L. A. Lochstoer (2010). "Long-run risk through consumption smoothing," Review of Financial Studies 23(8), 3190-3224.

Karantounias, A. (2018) "Optimal fiscal policy with recursive preferences," Review of Economic Studies, accepted.

Koopmans, T. (1960) "Stationary Ordinal Utility and Impatience," Econometrica, XXVIII, 287-309.

Kreps, D. and Porteus, E. (1978) "Temporal Resolution of Uncertainty and Dynamic Choice Theory," Econometrica 46: 185-200.

Laczo, S. and R. Rossi (2015) "Time-Consistent Consumption Taxation," Mimeo. 
Lucas, R. (1990) "Supply-side economics: an analytical review," Oxford Economic Papers, 42(2), 293-316.

National Statistical Institute. 2017. Aggregate Statistical Indicators. Available on-line at www.nsi.bg. Accessed on Oct. 21, 2017.

Schmitt-Grohe, S., and M. Uribe (2006) "Optimal Fiscal and Monetary Policy in a MediumScale Macroeconomic Model," in NBER Macroeconomics Annual 2005, pp. 383-425. MIT Press: Cambridge, MA.

Schmitt-Grohe, S., and M. Uribe (2007) "Optimal simple and implementable monetary and scal rules," Journal of Monetary Economics, 54, 1702-1725.

Turnovsky, S. J. (2000) "Fiscal policy, elastic labor supply, and endogenous growth," Journal of Monetary Economics, 45, 185-210.

Vasilev, A.Z. (2018a) "An RBC model with Epstein-Zin (non-expected-utility) recursive preferences: lessons from Bulgaria (1999-2016)," Mimeo, University of Lincoln, UK.

Vasilev, A. (2018b) "Optimal Fiscal Policy in the Presence of VAT Evasion: The Case of Bulgaria," Czech Journal of Economics and Finance, 68(4), 399-414.

Vasilev, A. (2018c) "Optimal Fiscal Policy with Utility-Enhancing Government Spending, Consumption Taxation and a Common Income Tax Rate: The Case of Bulgaria," Review of Economics, vol. 69(1), pp. 1-16.

Vasilev, A. (2018d) "Optimal fiscal policy with an environmental tax and abatement spending in a model with pollution and utility-enhancing environmental quality: the case of Bulgaria," Macroeconomics and Finance in Emerging Market Economies, forthcoming.

Vasilev, A. (2017a) "Business Cycle Accounting: Bulgaria after the introduction of the cur- 
rency board arrangement (1999-2014), European Journal of Comparative Economics, 14(2): 197-219.

Vasilev, A. (2017b) "VAT Evasion in Bulgaria: A General-Equilibrium Approach," Review of Economics and Institutions, 8(2): 2-17.

Vasilev, A. (2016) "Search and matching frictions and business cycle fluctuations in Bulgaria," Bulgarian Economic Papers BEP 03-2016, Center for Economic Theories and Policies, Sofia University St. Kliment Ohridski, Faculty of Economics and Business Administration, Sofia, Bulgaria.

Vasilev, A. (2015a) "Welfare effects of at income tax reform: the case of Bulgaria," Eastern European Economics 53(2): 205-220.

Vasilev, A. (2015b) "Welfare gains from the adoption of proportional taxation in a generalequilibrium model with a grey economy: the case of Bulgaria's 2008 flat tax reform," Economic Change and Restructuring, 48(2): 169-185.

WDI (2015) World Development Indicators. Available on-line at www.worldbank.org/data/wdi. Accessed on Oct. 21, 2015.

Weil, P. (1990). "Nonexpected utility in macroeconomics," The Quarterly Journal of Economics 105(1), 29-42.

Zhu, X. (1992) "Optimal Fiscal Policy in a Stochastic Growth Model." Journal of Monetary Economics, 58:250-289. 